\title{
LIBRE ALBEDRÍO. ¿Es REALMENTE LIBRE?
}

Free will. Is it really free?

\author{
Jorge Casas-Castañeda ${ }^{1}$ y Sebastian Casas- \\ Quaderer $^{2}$
}

\begin{abstract}
RESUMEN
La esencia del libre albedrio ha sido objeto de debate, por siglos, entre la filosofía y la religión, debate casi inexistente en las personas promedio, quienes suelen dar por sentado que las decisiones personales gozan de autonomía y libertad. El presente texto pretende dar una mirada más allá de la ideología y analizar la evidencia reciente sobre la contribución biológica y cultural en nuestro proceso de toma de decisiones y, en última instancia, en nuestra conducta.
\end{abstract}

Palabras clave: libre albedrio, valores, memes, conducta.

\begin{abstract}
The essence of Free Will has been the subject of debate, a centuries-old, between philosophy and religion, one that is nonexistent for the average person, who takes for granted that personal decisions enjoy autonomy and freedom. This paper seeks to look beyond ideology and analyze recent evidence of the biological and cultural contribution to our decision-making process and, ultimately, to our behavior.
\end{abstract}

Keywords: free will, values, memes, behavior

1 Médico internista. Profesor (r) de la Facultad de medicina, Universidad Peruana Cayetano Heredia, Lima, Perú.

2 Universidad de Berna, Suiza

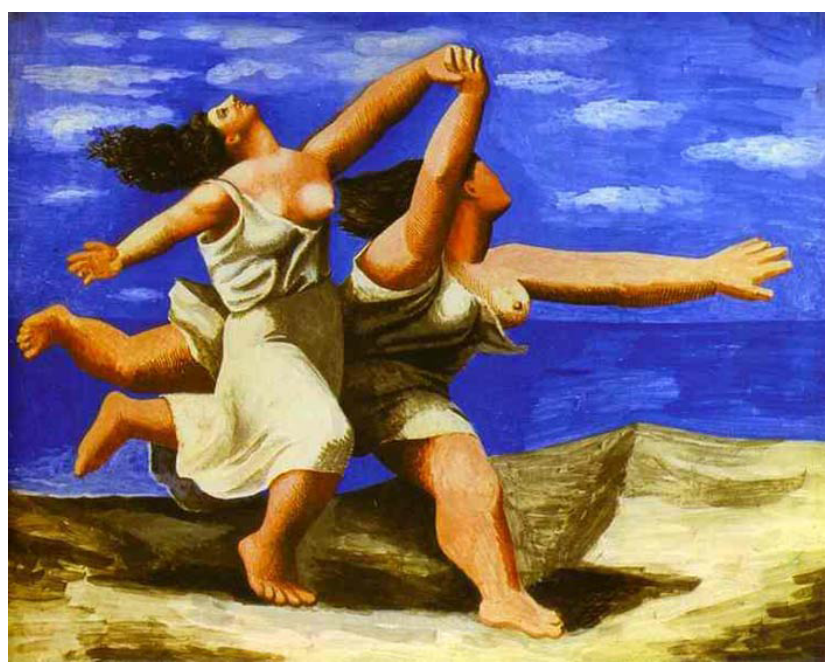

Dos mujeres corriendo en la playa. Pablo Picasso, 1922.

did 1 libre albedrio se le suele entender como la libertad de una persona de actuar de acuerdo a su motivación y elecciones que no están determinadas por causas previas o por la intervención divina". ${ }^{1}$

El debate sobre la existencia del libre albedrio es antiguo y ha enfrentado por siglos a filósofos y religiosos. 
Una de las conceptualizaciones más populares parte de la idea de que la voluntad para decidir libremente es inherente al ser humano mientras que para otros todo lo que sucede está determinado por lo que ocurrió antes y nuestras acciones son consecuencias inevitables de los eventos previos, concepción que hace imposible que alguien haga algo que sea verdaderamente libre. Encuestas recientes en el público general, revelan que más del $80 \%$ de la gente cree en el libre albedrío irrestricto ${ }^{2}$, con todas las implicancias morales, culturales y legales que este concepto en su acepción extrema implica. Este artículo tiene por objetivo dar una visión actual sobre este debate, basado más en los hechos que en las opiniones.

El proceso de decisión que culmina en la elección de una opción está sujeto en todos los casos a una serie numerosa de variables que se remontan al mismo momento de la concepción y que se dan a lo largo de toda la vida, variables que interactúan en cada decisión. A veces una variable es reforzada por otra y con frecuencia se oponen y entran en conflicto. Para fines de análisis en este trabajo, clasificamos estas variables como biológicas y culturales. Analizaremos algunas de estas variables para proporcionar una perspectiva del rol que juegan en el proceso de toma de decisiones.

\section{FACTORES Biológicos}

Algunas personas poseen el gen TAS2R38 que permite reconocer químicos amargos como las tioureas de ciertos vegetales, y quienes poseen este gen evitan estos alimentos. Este gen también influencia el consumo de alcohol. Lo que se percibe como una preferencia de gusto tiene en realidad es un poderoso factor biológico "oculto". ${ }^{3}$

El genoma en realidad contiene muchas versiones potenciales y la resultante final es el producto de variables a las que las personas están expuestas desde la concepción. La epigenética nos muestra los cambios químicos realizados en el $\mathrm{ADN}$, o proteínas que interactúan con el ADN afectan la actividad genética. También, nuestro microbiota es un factor ambiental significativo que afecta comportamientos tales como comer en exceso, la depresión etc. Los genes son las teclas del piano, pero el entorno toca la canción. ${ }^{4}$

¿Por qué nos suele atraer el sexo opuesto en vez del propio? Esta no es solamente una decisión consciente totalmente libre pues en gran medida nacemos así. Los componentes genéticos de la sexualidad humana no están completamente dilucidados, pero está claro que no se trata de una elección pura.

Para la sociedad y para la medicina (espejo social de los valores prevalentes de cada época), la homosexualidad fue consideraba una enfermedad mental, como figuraba en el Diagnostic and Statistical Manual of Mental Disorders (DSM-II). Recién en la versión del DSM de 1974 se cambió el termino de enfermedad mental por el de orientación sexual y, finalmente, en 1987 la homosexualidad fue retirada de la clasificación en el DSM-III-R como una condición mental. ${ }^{5}$

Ni siquiera la preferencia sexual es una opción totalmente libre. El análisis del genoma de casi 500000 personas muestra que el efecto genético es responsable de entre el $8 \%$ y el $25 \%$ de la variabilidad en la condición de homosexualidad. ${ }^{6}$ Entre las muchas variables que construyen una inclinación homosexual, una de significativo impacto es el número de hermanos varones mayores que aumenta la probabilidad en un 33\% sobre el valor base de la población ${ }^{7}$ y en un $84 \%$ sobre el valor base de no tener hermanos mayores a sólo hermanos mayores. ${ }^{8}$ El GWAS (Genome Wide Association 
Study), estudio de gran escala, revela la arquitectura genética del comportamiento sexual. La hipótesis es que, con subsecuentes embarazos de fetos masculinos, el útero desarrolla una respuesta inmune a los antígenos específicos masculinos ligados al cromosoma Y que estimulan la producción de anticuerpos anti-masculinos, lo que incrementa la aparición de la homosexualidad. ${ }^{9}$

En consonancia con la aceptación de raíces biológicas y ambientales más allá del libre albedrio, la sociedad está dejando de ver a la homosexualidad como un pecado o una enfermedad y aceptarla como una condición humana legitima. Independientemente de nuestra orientación sexual, tenemos un sentido innato de los atributos que encontramos deseables en una pareja. Características como una boca bien formada, ojos brillantes y cabello exuberante son ampliamente apreciados como atractivos. Y, los estudios muestran que las personas más atractivas son más propensas a conseguir un trabajo, ganar más dinero, encontrar un compañero, e incluso a ser declaradas "no culpables" si son juzgadas. ${ }^{10,11}$

Existen rasgos distintivos de personalidad que tienden a estar asociados con personas de extremos opuestos del espectro político, los liberales tienden a ser más abiertos, creativos y a buscar la novedad; los conservadores tienden a ser más ordenados y convencionales, y a preferir la estabilidad. Los gemelos idénticos, separados al nacer y criados en diferentes entornos, suelen tener posiciones políticas similares, lo que sugiere un componente genético para nuestra brújula política. Varios estudios sugieren que las variaciones en nuestro gen receptor de dopamina D4 (DRD4) influyen en la opción política. La dopamina es un neurotransmisor asociado con el centro de recompensa; $y$, las variaciones en el DRD4 están relacionadas con la búsqueda de novedades y la toma de riesgos comportamientos más comúnmente asociados con los liberales. ${ }^{12}$

Los conservadores tienden a tener una amígdala (el centro del miedo) más grande, y tienen reacciones fisiológicas más intensas a fotos o sonidos desagradables. Estas diferencias biológicas pueden explicar parcialmente por qué es tan difícil para un liberal o conservador conseguir que el otro "vea la luz". Solemos esperar que la gente no sólo cambie de opinión sino también que se resista a su biología. ${ }^{12}$

Todo comportamiento humano -desde la adicción hasta la atracción y la ansiedad- está atado a un ancla genética. Sin embargo, esto no quiere decir que estemos destinados a ser esclavos de nuestro ADN. Schopenhauer lo expresa de manera tanto elocuente como conmovedora: El hombre puede hacer lo que quiera, pero no puede escoger lo que quiere. ${ }^{13}$

Nuestro sistema nervioso producto de herencia y de cultura tiene programada una serie de expresiones que condicionan nuestra conducta. Esta visión intuitiva del libre albedrio ha empezado a analizarse con resultados que resultan contra intuitivos y la primera línea de evidencia proviene del estudio de la fisiología neuronal básica.

Se evaluó la actividad neuronal medida por fMRI que permitió a los investigadores predecir el momento de la decisión de actuar de la persona de prueba segundos antes de que fuera consciente de su propia decisión y antes de que actuara.14 En la elección de la actividad motora de movimiento para lograr un objetivo, nos parece intuitivamente obvio que las decisiones conscientes fueran la primera y principal causa de nuestro comportamiento. Sin embargo, evidencia reciente desafía esta interpretación del rol de la voluntad consciente y ha demostrado que 
algunas acciones se inician, aunque seamos inconscientes de las metas a alcanzar en nuestro comportamiento. El 'Bereitschaftspotential' (BP), o potencial pre motor, mide la actividad en la corteza motora ocupada en la preparación de un movimiento muscular voluntario, y es una manifestación de la contribución cortical al planeamiento del movimiento voluntario. El BP que inicia el movimiento voluntario, comienza fracciones de segundo antes de que la persona se dé cuenta de haber tomado esta decisión conscientemente. ${ }^{14}$ Este resultado ha sido reproducido y ampliado por grupos independientes ${ }^{15-17}$, indicando que la conciencia sobre la decisión de movimiento se produce después de que la decisión ha sido tomada por procesos neurales inconscientes. Estos estudios han tenido un gran impacto en el concepto clásico de la voluntad y es un argumento contra la existencia de una total libertad de elección. Indica al menos que algunas de nuestras acciones están determinadas por procesos neurales inconscientes y que la consciencia es un evento posterior a una actividad neuronal pre-consciente.

Si vamos más allá de la neurofisiología básica e ingresamos al campo más complejo de la conducta, se debe puntualizar que nuestras preferencias definen nuestra identidad y en gran medida caracteriza quienes somos, ya sea en comida, parejas románticas o candidatos políticos. La percepción prevalente es que la decisión de preferencias se construye a través de una cuidadosa deliberación y una toma de decisiones racional, en resumen, a través de selecciones que controlamos. ${ }^{18}$

\section{Microbioma}

Con más detreinta trillones demicroorganismos que habitan en cada uno de nosotros, no debería ser una sorpresa que la masa de genes en estas bacterias, virus y hongos (microbioma), influya diversos procesos internos y no solamente digestivos. Se ha empezado a documentar que nuestras mentes están influenciadas por nuestro propio microbioma. ${ }^{19,} 20$ Ya se conoce que la manipulación experimental del microbioma intestinal en roedores modifica el comportamiento emocional y cognitivo, la expresión de los neurotransmisores y la función cerebral. En humanos, un estudio aleatorio doble ciego vs placebo evaluó el impacto de cuatro semanas de administración de probióticos, se evaluaron diversos parámetros cerebrales utilizando resonancia magnética funcional. En el grupo de intervención, se documentó cambios en los patrones de activación del cerebro en respuesta a la memoria emocional y en el proceso de toma de decisiones emocionales. ${ }^{21}$ Estos resultados abren la opción de modificar el microbioma intestinal y obtener potenciales aplicaciones terapéuticas. Las emociones influyen nuestra percepción del mundo, organizan los recuerdos y cómo se toman las decisiones. Las áreas del cerebro asociadas con el procesamiento emocional están estrechamente conectadas con las regiones del cerebro responsables de la formación de la memoria y la toma de decisiones. La manipulación del microbioma puede influir en los mecanismos cerebrales que subyacen al procesamiento de la memoria y la toma de decisiones en un contexto emocional. Sin embargo, ciertamente no pretendemos sugerir que sólo somos robots biológicos bajo la influencia de fuerzas invisibles

\section{Factores Culturales}

Meme:Término acuñado por Richard Dawkins, un meme es una unidad de información cultural que se transmite por imitación, a través del habla, la escritura, los gestos, los rituales $\mathrm{u}$ otras actividades imitables. Al igual que los genes, a los cuales los memes son análogos culturales, se autorreplican, mutan y, lo que 
es más importante, están sujetos a presiones externas. En lugar de competir por una capacidad reproductiva limitada, compiten por un lugar permanente en nuestras mentes. Algunos disfrutan de un gran éxito mientras que otros se extinguen. ${ }^{22}$

Una de las aplicaciones más extendida/ abusada de los memes para alterar el comportamiento se llama marketing. En 1929, el inventor de las relaciones públicas, E. Bernays, lanzó una de las primeras campañas de marketing para incitar a las mujeres a fumar cuando contrató a las chicas que participaban en el desfile del Domingo de Pascua, en Nueva York, para que fumaran cigarrillos en público, un acto considerado tabú en aquella época. Luego, también informó a los medios de comunicación que eran sufragistas (activistas del derecho al voto femenino) y que se manifestaban con sus antorchas de libertad en alto, haciendo referencia a la Estatua de la Libertad. Esta frase apareció en todos los periódicos y muchas mujeres interesadas en el voto se unieron a la Dama de la Libertad con sus propias antorchas de libertad..$^{23}$ Una fortuna se invirtió en los siguientes años en un marketing dirigido a incrementar el uso del tabaco, inversión que tuvo un gran retorno. Las mujeres fumadoras en Estados Unidos de Norteamérica incrementaron de $4 \%$ en 1927 al $42 \%$ en $1971 .{ }^{24}$ En la década de 1970 se hizo extensa publicidad sobre los riesgos del tabaco y el meme que llevaba al consumo de cigarrillos atenuó y con ello el consumo se redujo. Ejemplo que muestra la influencia de factores externos tipo "memes" en nuestro proceso de toma de decisiones.

Valores: Los valores juegan un rol importante en el proceso de toma de decisiones, se adquiere en su mayor parte en el proceso de socialización, que se da entre los 3 y 12 años de edad, por lo cual el rol de la familia nuclear es central, pero no exclusiva. En grado variable, también contribuyen a formar/deformar valores la familia extendida, colegio, amigos, los medios, etc.

Vamos a analizar un valor, el de "generosidad" para dar una imagen de lo que sabemos de este complejo tema de los valores. Solemos pensar en la generosidad como una evidencia pura y noble del alma, más que como un tema encefálico con una base biológica y circuitos condicionados en la infancia. Evolutivamente, la generosidad es una extensión de la cooperación que es una de las piedras angulares del éxito humano. La temprana interacción económica humana se reducía al trueque, en grupos tribales pequeños donde las deudas interpersonales eran fácilmente recordadas. A medida que se intensifica el trueque, la confianza, otro componente clave para la cooperación, crece. La confianza es especialmente importante en situaciones de emergencia como en una cacería, durante un incendio o una hambruna. Los individuos se inclinan más a compartir, a ser generoso, con alguien en quien confían. La evolución hace que el comportamiento que es beneficioso para una especie se sienta bien para el individuo, ya sea consiguiendo y compartiendo comida, abrigo, apoyo emocional etc. ${ }^{25}$

Sabemos ahora que los actos de generosidad activan regiones responsables del pensamiento racional y también se activan centros de placer, asociados con la comida, el sexo y las drogas. El impulso de dar surge de una mezcla de apetitos básicos y reflexión refinada, una combinación potente adquirida en la evolución de la humanidad.

Esta compleja regulación encefálica queda dramáticamente ejemplificada en el caso de un paciente de 49 años, previamente normal, quien luego de sufrir un hematoma 
lenticulocapsular izquierdo, recuperó la misma capacidad cognitiva y motora que tenía previo al evento cerebrovascular. En las semanas siguientes fue notable notar la presencia de una generosidad excesiva y persistente, que no existía previamente. Esta generosidad patológica generó un cambio de comportamiento radical que lo llevo a compartir o regalar indiscriminadamente sus bienes. Su situación social de clase media próspera en pocos años paso al de mendigo y aun en esta condición siguió mostrando una generosidad desmedida. ${ }^{26}$ Este paciente nos muestra que los valores no tienen una base solo cultural, existe un sustrato encefálico innato con el que nacemos y que la evolución nos ha otorgado. Esta misma base neuronal puede modificarse por afecciones cerebrales de diverso tipo.

\section{Conclusiones}

La evidencia científica reciente demuestra que nuestro libre albedrio no es tan libre, como es convicción mayoritariamente extendida y tiene determinantes subyacentes significativos. Hay mecanismos biológicos y culturales que modulan cada acción y cada rasgo de personalidad. Conocer la base molecular y cultural de nuestras conductas positivas y negativas nos ubica en una mejor posición para entenderlas mejor y optimizarlas; aceptar que otras personas tienen pocas opciones en cuanto a cómo llegaron a ser debe engendrar más empatía y compasión. Tal vez, con la confianza de que no tenemos el control total podamos aminorar el impulso de alabar o culpar, y privilegiar más la comprensión.

\section{REFerencias BibliogrÁFicas}

1. Oxford. Free Will. URL disponible en https://www.lexico. com/definition/free_will. (Fecha de acceso: 7 de julio 2020.

2. Wisniewski D, Deutschländer R, Haynes JD. Free will beliefs are better predicted by dualism than determinism beliefs across different cultures. PLoS One. September 2019;14(9).

3. Duffy VB, Davidson AC, Kidd JR, Kidd KK, Speed WC et al. Bitter Receptor Gene (TAS2R38), 6-n-Propylthiouracil (PROP) Bitterness and Alcohol Intake. Alcoholism Clinical and Experimental Research. May 2006. 28(11):1629-37.

4. Sullivan B. Why we like what we like. National Geographic. September 2019.

5. Burton N. When Homosexuality Stopped Being a Mental Disorder. Psychology Today. March 2020. url Disponible en https: / / www.psychologytoday.com/us/blog/hideand-seek / 201509/ when-homosexuality-stopped-beingmental-disorder. Obtenido el 1.7.2020

6. Ganna A, Verweij KJH, Nivard MG, Maier R, Wedow R, Busch AS et al. Large-scale GWAS reveals insights into the genetic architecture of same-sex sexual behavior. Science. 2019 Aug 30;365(6456), eaat7693. https:// doi.org/10.1126/science. aat7693

7. Blanchard R. Homosexuality in men and number of older brothers. American Journal of Psychiatry. January 1996. 153(1):27-31.

8. Vanderlaan DP, Blanchard R, Wood H, Zucker JK. Birth Order and Sibling Sex Ratio of Children and Adolescents Referred to a Gender Identity Service. PLoS One. March 2014. 9(3)

9. Blanchard RPK. H-Y antigen and homosexuality in men. Journal of Theoretical Biology. April 1997. 185(3).

10. Hollier R. Physical Attractiveness in the Legal System The Law Project. Marzo 2017. Obtenido en junio 2020. URL disponible en URL: https://www.thelawproject.com.au/ insights / attractiveness-bias-in-the-legal-system

11. Jaeger B, Sleegers W, Evans A, Stel M, Van Beest. The effects of facial attractiveness and trustworthiness in online peerto-peer markets. Journal of Economic Psychology. 75. 10.1016/j. joep.2018.11.004.

12. Ebstein RP, Monakov MV, Lu Y, Jian Y, Lai SP et al. Association between the dopamine D4 receptor gene exon III variable number of tandem repeats and political attitudes in female Han Chinese. Proceedings of the Royal Society B. 282: 1813

13. Kanai R, Feilden T, Firth C, Rees G. Political Orientations Are Correlated with Brain Structure in Young Adults. Current Biology. April 2011. 21(8):667-70

14. Schopenhauer A. Essays und Aphorisms. Tredition Classics. Hamburg: tredition $\mathrm{GmbH}$. May 2012.

15. Guggisberg AG, Mottaz A. Timing and awareness of movement decisions: does consciousness really come too late? Frontiers in Human Neuroscience. Julio de 2013.

16. Custers R, Aarts H. The Unconscious Will: How the pursuit of goals operates outside of conscious awareness. Science. July 2010. 329(5987):47-50.

17. Haggard P, Eimer M. On the relation between brain potentials and the awareness of voluntary movements. Exp Brain Res.199;126:128133.

18. Soon CS, Brass M, Heinze HJ, Haynes JD. Unconscious determinants of free decisions in the human brain. Nature Neuroscience. June 2008. 11(5):543-5.

19. Rigoni D, Pourtois G, Brass M. 'Why should I care?' Challenging free will attenuates neural reaction to errors. Social Cognitive and Affective Neuroscience. February 2015. 10(2): 262-8.

20. Pessoa L. On the relationship between emotion and cognition. Nat Rev Neurosci. 2008;9:148-58. doi:10.1038/nrn2317.

21. Bagga D, Reichert, JL, Koschutnig K, Aigner CS, Holzer P et al. Probiotics drive gut microbiome triggering emotional brain signatures. Gut Microbes. 2018 Nov 2;9(6):486-496.

22. Dawkins R. The Selfish Gene. Oxford University Press; 1990. 
23. Amos A, Haglund B. From social taboo to "torch of freedom": the marketing of cigarettes to women. Tobacco Control. March 2000;9(1):3-8.

24. Lund KE, Lund M, Bryhni A. Tobacco consumption among men and women 1927-2007. Tidskrifted. September 2009. 18(129): 1871-4

25. Park SQ, Kahnt T, Dogan A, Strang S, Fehr E et al. A neural link between generosity and happiness. Nature Communications. Jul 2017. 8(15964).
26. Ferreira-Garciam R, Fontenelle LF, Moll J, de Oliveira-Souza R. Pathological generosity: An atypical impulse control disorder after a left subcortical stroke. Neurocase. 2014;20(5):496-500.

\section{CORRESPONDENCIA}

\section{jorge.casas12@yahoo.com}

Fecha de recepción: 14-07-2020.

Fecha de aceptación: 11-01-2021.

Conflicto de interés: ninguno según los autores.

Financiamiento: por los autores. 